\title{
Introducing Biodynamic Craniosacral Therapy (BCST) into the Landscape of Jungian Thought
}

\author{
Jane E. Shaw, M.A.*
}

Pacifica Graduate Institute

\begin{abstract}
Whereas research in the craniosacral field tends to focus on the benefits for the individual, in this paper I go a step further to argue that because of its psychoid nature, biodynamic craniosacral therapy (BCST) acts as an embodied practice to raise earth consciousness at both the collective and individual levels. The therapy is a light-touch practice grounded in empathetic presence in which practitioners work to attune the subtle rhythms of their own body, the client's body, and the "body" of the environment and natural world in which they meet. Referencing my clinical experience, the essay proposes that craniosacral biodynamics, bringing consciousness to the human organism, may offer a felt experience of the interconnectedness of all being, even bringing to consciousness our relationship with the earth itself. This essay highlights where Jungian theory and BCST not only overlap but also where they might support each other to revision our relationship to the planet.
\end{abstract}

As a practitioner and teacher of biodynamic craniosacral therapy (BCST), I draw from my clinical practice to examine a rationale for a felt experience of the interconnection of all being by describing my observation of several typical clinical cases. Being also a Jungian psychologist I recognize not only that Jungian theory and BCST overlap but also that they might facilitate a revisioning of our relationship to the planet. This essay examines these possibilities.

BCST is a therapeutic light-touch practice in which the practitioner attunes the subtle rhythms of the client's body, as a human organism, to the subtle rhythms of the "body" of the environment and natural world. These rhythmic motions are known in BCST as Primary Respiration. Assuming the key Jungian position that the psyche is real and has a collective aspect, meaning that it is more than the individual (Jung 1947/1969, p. 151), I suggest that BCST practice is a lived experience of what Jung (1947/1969) calls the psychoid reality, where psyche and matter are one and the same (p. 148). Whereas research in the craniosacral field tends to focus on the benefits for the individual, in this paper I go a step further to argue that because of its psychoid nature BCST acts as a practice to raise an embodied awareness of the earth, at both

*jane@janeeshaw.com 
the collective and individual levels. Thus, arguably the BCST practice can benefit the earth as well as the individual.

While the connections are not absolute, there does seem to be value in exploring craniosacral practice as a means to better understand Jung's (1947/1969) concepts of the psychoid reality. At the same time, Jungian theory can give insights into the nature of cranial biodynamic practice to develop our conscious relationship with the earth. Since there is little research on the connection between craniosacral therapy and Jungian theory, apart from a few excerpts in Shea (2007), I shall look directly to Jung, as well as to the work of post-Jungians Corbett (2014) and Goodchild (2012), and to the work of BCST authors Becker (1997), Shea (2007), Sills (2001), and Sutherland \& Wales (1990) to draw parallels between the psychoid nature of craniosacral practice and Jungian theory.

A BCST practitioner tunes into what is known as Primary Respiration, which is the phenomenon of subtle rhythms that occur within and around the body-mind continuum as a human organism. Primary Respiration is thought to arise from an intrinsic ground of deep stillness that pervades all life forms (Sills, 2001, p. 51). The pioneering founder of craniosacral therapy, Sutherland (1990), observed that there are fluid tidal rhythms within the human system that skilled practitioners could feel with their "thinking, feeling, seeing, knowing, touch" (p. 14). He further believed there is an intelligence, separate from our thinking minds, that drives these fluids. His theory was that a skilled practitioner's presence and touch reignites the knowing intelligence and reminds clients of their intrinsic self-healing mechanism. Becker (1997), another pioneer of this work, claimed, "There is a basic primary rhythmic interchange taking place in all that is alive" (p. 16). In other words, there is a fluid interconnection between beings, individually and collectively. While the subtle rhythms described by both Becker and Sutherland are not scientifically proven, there do seem to be useful parallels with Jungian theory: the cranial model can offer an embodied experience of psychoid theory, and a Jungian lens can offer insights into what is happening during cranial practice.

Jungian theory and BCST share the quest to uncover what we cannot see, in other words the unknown. Jung (1939/1991) calls this unknown the unconscious whereas in my therapeutic practice we might call it the unseen contents of the field (Sills, 2001). Further, according to Jung (1947/1969) the unconscious has both a collective and personal aspect while early BCST theorists, like Sutherland (1990), talked about the interconnection of all being, suggesting the same collective principle. The practice of BCST facilitates conscious whole body listening to the deep patterns held in the client's body, allowing understanding of the meaning that those patterns might hold, as I will demonstrate using clinical examples. This means that practitioners use all their feeling and senses to assess what is being expressed in 
the client's system. For example I may sense a muscular tension pattern around the hip but at the same time see an image of a childhood experience.

Jung (1939/1991) maintained that the unconscious, the unknown part of the psyche, is ordered by primordial images or patterns that he called archetypes (p. 58), which Jung (1947/1969) considered "formative principles of instinctual power" (p. 212). He argued that while an archetype per se can never be truly known, it can appear as an archetypal image, such as the archetypal mother or father that is often projected onto the actual mother or father in the external environment. This projection is a way to make the unconscious archetypal content conscious. However, in a moment of synchronicity, defined by Jung (1960/2010) as a "meaningful coincidence" (p. 10), there can be a break through where consciousness comes into touch with the archetypal order (p. 148). The psychoid reality is a "quasi-psychic" notion (Jung, 1947/1969, p. 102) where psyche and matter are one and the same (p. 148). I believe that it is this quasi-psychic juncture that BCST practice inhabits.

The main BCST schools today teach that the practice has resonances with the Taoist principle of $W u W e i$, the art of "doing non-doing" (Sills, 2001). Jung (1929/1967) also spoke about Wu Wei in observing that people seemed to "bring about development that set them free," but as far as he could see "they did nothing (wu wei) but let things happen" (p. 16). In the practice of doing nondoing, when the practitioner has a felt sense of the underlying stillness, something happens. Becker (1997) highlighted that it is not the therapist who creates the transformation; rather it is from the stillness that answers of intuitive knowing arise that can create profound change in body and psyche. Often clients do not know specifically what happened, but after a session they may report feeling more connected to what they might describe as their authentic being and a deep knowing that they cannot explain. Additionally, a sense of embodied wholeness can be palpable for even the most dissociated clients, meaning that where they were perhaps not able to sense their body, they have a better knowing of how the separate parts are connected - there is a felt sense of ease and flow. This practice is not about fixing the client; rather it is about supporting clients to be in a conscious relationship with where they are today, with their being, with others around them, and with the earth. Becker (1997) speaks of this experience:

When I tune into a relative stillness within the patient, even before I start working, I am in tune with the very foundation of that patient's being, which is also a similar, tide-like movement. . . . I can then do whatever needs to be done; I work without regard to what I hope to accomplish for that patient. I simply go to work. (p. 17)

The notion of $W u W e i$ aligns with the idea that there is no one in control; rather there is a higher intelligence affecting the change, which suggests that there might 
be a creative regenerative impulse in the body and psyche. Jung (1939/1991) said that the collective and personal contents of the psyche are in continual movement towards wholeness and integration, a movement that he called the individuation process (p. 275). There is a drive, therefore, whether from a Jungian or cranial perspective, for the individual to become conscious of the unseen parts of the psyche and thereby to move towards wholeness. We do not need to try to change anything since order or patterning is archetypal.

Jung (1929/1967) wrote that through a Wu Wei practice one is taken to an inner space of unity. "Through the ritual action, attention and interest are led back to the inner, sacred precinct, which is the source and goal of the psyche and contains the unity of life and consciousness" (p. 25). Arguably this sentiment aligns with a BCST treatment in which the client can reach deep levels of stillness from which new possibilities emerge. Shea (2007) combining metaphors originally used by Sutherland (1990) to describe BCST, explained that "the heart is ignited by the union of Dynamic Stillness and the spark of the Breath of Life" (p. 164), where Dynamic Stillness is the emptiness from which life emerges, and the Breath of Life is an intelligence that moves the subtle rhythmic tides. The Breath of Life might be compared to the Jungian Self as a centralizing ordering archetype or "God-image" (Jung, 1950/1981, p. 22). It seems that at the exact point in time of the ignition there is something at once knowable and unknowable, where the conscious and unconscious meet.

Jung (1929/1967) identified another notion that describes BCST practice. He referred to an observation of a man whereby "ordinary breathing stopped and was replaced by an internal respiration, 'as if by breathing of a distinct personality within and other than the physical organism"' (p. 27). The breathing referred to in BCST is not respiratory or lung breathing. Instead, like Jung seemed to imply, it is experienced in cranial work as a breathing by an intelligence as if from outside the human organism - the human system is "being breathed." In my experience, it is the primary respiration or tidal movement described by Sutherland (1990) that links the outer and inner. Taking the experience into the psychoid realm as our awareness expands is, I think, the key to bridging consciousness that arises among a client, practitioner, and the earth. It is as if there is a universal tidal rhythm that drives both the rhythms in the human organism and the rhythms in nature.

\section{Clinical examples}

Since BCST practice is not widely known and not always easy to understand through theory, I shall describe some typical client sessions to illustrate my central idea that BCST inhabits the psychoid realm. Typically, a session lasts for an hour during which clients lie on a treatment table fully clothed and with blankets, pillows, and cushions making them as comfortable as possible. The practitioner makes a 
therapeutic relationship through very light touch and works largely in the region of the head, spine, and sacrum, although contact may be made with any area of the body. The clinical sessions here have been described to protect the identity of the client; for example, names have been changed.

Session one: As practitioner, I report the following: My house electrics blow just before Sheila arrives, making me wonder who is this new client and what will she bring into the clinic room. Sheila lies on the table with a red blanket covering her. I notice how it is twisted in a pattern pulling towards her left leg. I think to straighten it but decide to leave it. There is a fly buzzing around the office. It is distracting. Sheila's system is in high sympathetic arousal, the fight-or-flight mode. I sense her system is agitated, like the fly. I too am agitated. I notice the wind outside whirling around, picking up and dropping leaves. I tune into my own sense of somatic self and allow it to settle deeply. I bring my awareness to my own spine, connecting to the earth beneath me, my physicality acting as a fulcrum for this session. Sheila takes a deep breath. She starts to let go. She mentions a memory of being in hospital as a child. I am drawn again to this red pull in the blanket; I want to straighten it again, but I don't. I am holding her feet, so I move to her spine. I place one hand under her lower spine at the side of the table and one hand on her right hip. The wind is picking up again outside. The rhythms in her system are running fast, and I feel she wants to bolt out of the room. I check in with her while at the same time I again ground my own body and slow down my own internal rhythm. She mentions again the hospital stay when she was a two-year-old. There were metal bars around the bed. She is agitated again. While I stare agitatedly at this red blanket twisting towards her right inner thigh, she tells me she had an emergency blood transfusion injected into her right femoral artery: the exact place of the red twisted blanket. As a two-year-old she had to be held down by the doctors. Once she has named the event, she brings her awareness to her physical body in the present moment, and she calms immediately. I notice that the fly has settled quietly on the window. The wind outside has settled. I wait, check in with my own body. There is a deep quiet in the whole room. Then the sun breaks through the clouds, flooding the room, just as a wave of vitality flows through Sheila's body from her feet to her head. Something big just happened in her body. I don't need to know more than that.

In this clinical example, it is possible to see where the experiences of both myself as practitioner and of Sheila as client, inhabit psychoid space. The awareness of both of us has expanded to include connections that were hitherto unseen or unconscious. By noticing all the subtle movements and responses in my own physical body while maintaining a deep meditative presence, I heighten my awareness to expand out toward the client, the room, and further into nature outside the room. Debatably, my experience as practitioner of the session is situated in the liminal reaches of the unconscious. When practitioners bring consciousness to their 
whole being and all that is within, which BCST practice calls the field, something shifts for the client. Something deep inside Sheila connected her present-day bodily patterning with childhood experiences, and when the conscious connection is made the organism can transform. Jung (1939/1991) said, "The symbols of the self arise in the depths of the body and they express its materiality every bit as much as the structure of the perceiving consciousness" (p. 173), emphasizing the importance of symbols that arise from the unconscious. Symbols in Jungian terms are paths to the unknown, so they bring formerly unconscious contents into our conscious awareness. Jung (1953/1972) stressed that what he meant by the term symbol was "something that is still entirely unknown or still in the process of formation" (p. 291), so it is different from a "sign" that "disguise[s] something generally known" (p. 291). Therefore, the symbols arising from the body-mind are coming from the unconscious, and we will not have known about their meaning before. I think that this process of symbol formation and its transformative power are demonstrated in BCST practice.

Jung's (1960/2010) notion of synchronicity suggested that "meaningful coincidences," such as the red blanket, the fly, and the wind, demonstrated in Sheila's session, "rest on an archetypal foundation" (p. 440). He famously described a clinical case in which his client dreamed of a scarab beetle, and as she described her dream an actual scarab beetle tapped on Jung's clinic window (p. 438). The importance of the synchronicity is to make conscious the connection of the inner psychic contents and apparently acausal external events. In the session with Sheila, her physical presentation appeared to mirror her inner psychic contents.

An embodied conscious awareness of the interconnection between ourselves and our surroundings is important because it is our innate indigenous sensibility to connect with the earth, yet in our modern western world our fully embodied being has largely been forgotten as a medium to connect with the natural world, despite our evolutionary way of communicating and responding to the earth, plants, and animals. More commonly our sense of our body is largely unconscious. In the BCST practice a greatly expanded awareness occurs, lifting the body-mind continuum out of its old patterns and facilitating a reorganization towards a conscious relationship with health and wholeness, which Jung (1939/1991) refers to as the healing relationship with the Self, the totality of one's being.

Jungian writer Goodchild (2012) explored how the imaginal realm can be helpful in connecting us more deeply to each other and the world around us. She indicated that we can never be completely aware where matter becomes psyche and where psyche becomes matter. By opening our senses we can experience the world in a more expansive way, a principle central to this somatically centered practice. Goodchild proposed a new perspective based on the subtle body world, inviting us to see what is possible at the psychoid level. The session so far described in this essay 
implies how there is a "dynamic interconnectivity going on all the time in the tiniest of invisible places" (Goodchild, 2012, p. 35). I suggest that this subtle body awareness demonstrates an embodied imaginal route to communicating with the natural world. As my first session with Sheila demonstrated, if the practitioner sees the symbolic in all the aspects of the session - the red blanket, the fly, the electrics, the wind and the sun-noticing all their particulars rather than being distracted by the history of the pathology (which tends toward a literalization), then the practitioner "gets to the soul."

Sensing our physical selves connects us to the earth by attuning us to the psychematter continuum. Jung (1939/1991) supported this view by arguing that "The human body, too, is built of the stuff of the world, the very stuff wherein fantasies become visible; indeed, without it they could not be experienced at all" (p. 172). He suggested that as we withdraw further into the symbol, the psyche becomes both more "collective and universal" and "more material" (p. 173). Indeed, Becker (2000) echoes Jung's thinking by teaching that the deeper the physician goes within himself to listen, the greater the effect of the universal principle of what he calls, the "Light, Oneness or the Breath of Life" (p. 188).

To underscore the possible relationship to Jung's notion of the Self in BCST practice it is necessary to highlight Jung's (1939/1991) teleological perspective that was towards wholeness via the path of what he termed individuation. The autonomous nature of the unconscious has a teleological drive towards wholeness and through individuation, the different parts of the psyche are brought together to form a more conscious and differentiated whole. It is important to note that individuation is not necessarily individualistic, since one separates out to find oneself to better serve the whole. It will necessarily involve relating to the archetypal energies within the psyche. Since the teleology of BCST is also to orient to wholeness, it follows then that a relationship with the Self is also the teleology of BCST practice in which we come into relationship with the archetypes via the human organism. Often clinical experience suggests that the practitioner is witnessing the emergence of the Self, as the client emerges from what the practitioner senses as a fragmented state into a state of wholeness where the tidal rhythms are in harmony with each other. In the session with Sheila, the move towards the quiet room, the settled body, the dying wind, and the still fly all hint at harmony of inner and outer. Jung's point was that as individuals we progress towards a conscious relationship between the ego and the Self. This sentiment appears to parallel the process of biodynamic craniosacral therapy, which facilitates conscious awareness of separate parts of the body-mind, creating an integrated sum of parts and a connection to the outer world. It seems that cranial practice is also facilitating an individuation process. 
In a subsequent clinical visit by Sheila, a symbolic movement towards the center highlighted a relationship between the Self and the human organism as bodymind continuum.

Session two: I sit waiting for Sheila to arrive. It is sunny outside, a typical crisp bright autumn day. The room feels still. I notice a pull in my belly. Sheila arrives, wet and flustered. She is late. I give her space and time to settle herself. She reports that she feels more connection between her pelvis and her upper body. Then she lies down on the table. I am drawn to a painting on the wall, a blue spiral. I feel another pull in my belly. I check in with Sheila, asking what she notices in her body. She notices a gap between the table and her lower back. Her back is arched. I notice a place of felt absence around her umbilicus, her belly button. I cannot sense anything there. The rhythmic tides do not flow through her belly. A bird is sitting in the tree outside. The tree has lost its leaves and is still. The bird is still. I am still. Sheila is still but feels empty. I orient to my own midline, an axis running from high in the heavens deep into the earth. I feel a strong connection to the earth. I feel like the tree outside, being nourished by the rich earth. Shelia takes a deep breath. The arch in her back drops. Warmth comes to my hands that are either side of her umbilicus. She takes another deep breath. A wind appears outside. I hear a resounding chirping from the bird in the tree. Its musical notes echo round the room. Sheila smiles. She says she has a warm glow, saying she feels as if she is being held as a baby. A reflection causes a bright glare of sun into the room. A red fiery glow spreads through my hands and my own body. I take a deep sigh. Something lets go in the field. Something ignites in Sheila's body. We both smile. We don't need to talk. I note that it feels as if she has just been born.

As in the session with Sheila, BCST supports the transformation of the body from one constellated pattern to another, bringing an embodied awareness of something more. In my clinical experience, BCST can be viewed as a therapeutic touch session in which a transformation of the client's relationship to the Self occurs when the archetype of the center and of wholeness is made conscious via the bodymind continuum. Supporting this view, Corbett (2014) contended that a felt experience of the body can take us to the Self, saying that we do not need religions and belief systems to be in touch with transpersonal awareness despite our conditioning, since "the silence of the Self [is] immediately available as a felt sense in the body" (p. 11). In the second session with Sheila my interpretation is that she relived a birthing experience in which she could stay more conscious than during her actual birth. From my perspective, there is both: 1) an orientation around the umbilical center that is a center of organization in craniosacral terms; and 2) a drive toward integration that is organized around a midline axis or an umbilical axis. Perhaps she maintained a conscious relationship with the archetype of wholeness, the Self. If this is the case, then BCST practice may allow the emergence of the Self 
via the body, through the expanded psychoid reality, although the debate remains open since these concepts are intangible.

\section{BCST practice outside the clinic}

I have described two typical sessions in which I am acting as practitioner by feeling the interconnection of all things. However, in order for this to be a useful therapy for the ordinary person, the practice needs to become more widely available. When I teach people to become craniosacral therapists, I help them develop the ability to sense the body's subtle rhythms. The learning process involves simple body-oriented awareness practices that promote subtle connections to non-human life and inanimate objects. I offer these awareness-exercise workshops to the general public, who are all non-practitioners. My experience shows that these practices can allow a felt sense of the intimate reciprocal relationship of everything around us. What follows is an example of one of these exercises.

Session three: I instruct the group to choose a plant that they are drawn to and direct them as follows: Sit with the plant for 10 minutes, notice everything about it, touch it, smell it, listen to it with your whole-body awareness. Notice how your senses respond to being with it. Does your body change as you sit there? Does your body feel contracted, expanded, soft, warm, dense, light, peaceful, or agitated? John chooses an aloe vera plant that is in the classroom. He reports: It is a young plant, little, new shoots in a small pot. The pot is pink. The pink plastic pot doesn't seem right for this young green thing. There are four shoots, two long and two shorter. I touch it, and it feels delicate, velvet like. I feel tender in my body. There is a withered shoot. I wonder what happened to cause this shoot to die. It doesn't look healthy. I want to help it. I feel sad but protective, as I would with a child or a dog. There are little spikes starting to grow out of the stems. Are they stems? I'm not supposed to try to understand its biology, just notice. But I cannot help wondering whether these shoots are stems or leaves or what. I look more closely: one shoot is almost translucent, so that I can somehow feel the gel or sap inside. It feels soft but alive. Who was tending it, watering it? I talk to it. I've never spoken to a plant before. I feel a huge tenderness and a stillness in myself. Now this plant is like my child. I want to take her home and nurse her back to full health. I feel self-conscious and look around the room in case anyone has seen me talk to a plant. I'm tearing up. I pull myself together.

John's experience, I think, demonstrates how it is possible for one's awareness to expand into the psychoid realm. With practice the expanded consciousness starts to heighten all the five senses and may even tap into something commonly called a sixth sense. This kind of deep embodied listening allows us to cross the divide to hear what the earth is saying. Abram (1997) warned us that indeed we must change our perspective lest we cut ourselves off from the earth. "To define another being as 
an inert or passive object is to deny its ability to actively engage us and to provoke our senses; we thus block our perceptual reciprocity with that being" (p. 56). He urged us to see the living soul in everything, not just in animate beings. BCST might reintroduce the practices of our ancestors to our everyday experience.

It is also important to caution against these practices becoming a technique with a purpose, for example to fix or heal. In my experience, as soon as they become formulaic, they are concretized, and with that the archetypal nature of the effect on the human organism is lost along with the connection to the unconscious. It is important to continue to open into the imaginal, opening imaginal door after door. Only then will practitioner and client usher into consciousness the archetypal affect.

Developing a more fully conscious sense of ourselves as more fully embodied beings develops more consciousness of our surroundings and therefore of the earth. The exploration in this essay highlights not only how Jungian theory and craniosacral therapy intersect but also where they might support and develop each other to revision our relationship to the planet. Since the aim in craniosacral practice is to be in conscious relationship with the energetic field, it allows us to glimpse universal principles, such as Jungian archetypes, through individual experience. If the BCST practice expands our awareness to the psychoid reality, thus taking us to a more conscious relationship with the Self, it may then follow that it offers us more conscious choices over how we respond to ourselves, others, and the planet.

\section{Works Cited}

Abram, D. (1997). The spell of the sensuous. New York, NY: Vintage.

Becker, R. E. (1997). Using the aliveness (Ed. Brooks, R.). Life in motion (pp. 16-18). Portland, OR: Stillness Press.

Becker, R. E. (1997). Be still and know (Ed. Brooks, R.). Life in motion (pp. 24-38). Portland, OR: Stillness Press.

Becker, R. E. (2000). Correspondence: William G. Sutherland. (Ed. Brooks, R.). The stillness of life (pp. 178-219). Portland, OR: Stillness Press.

Corbett, L. (2014). Silence, presence, and witness in psychotherapy. In Echoes of silence: Listening to soul, self, other (pp. 7-26) Jungian Odyssey 2013. New Orleans, LA: Spring Journal.

Goodchild, V. (2012). Songlines of the soul: Pathways to a new vision for a new century. Lake Worth, FL: Nicolas-Hays.

Jung, C. G. (1967). Commentary on The secret of the golden flower. In R. F. C. Hull (Trans.), Alchemical Studies (Vol. 13, pp. 1-56). Princeton, NJ: Princeton University Press. (Original work published 1929)

Jung, C. G. (1969). On the nature of the psyche. In R. F. C. Hull (Trans.). London, UK: Routledge. (Original work published 1947)

Jung, C. G. (1972). Two essays on analytical psychology. In R. F. C. Hull (Trans.). Princeton, NJ: Princeton University Press. (Original work published 1953). 
Vol. 12, No. 1, 2017

Jung, C. G. (1981). The syzygy: Anima and animus. In R. F. C. Hull (Trans.), Aion: Researches into the phenomenology of the self (Vol. 9i, pp. 11-22). London, UK: Routledge. (Original work published 1950)

Jung, C. G. (1991). The psychology of the child archetype. In R. F. C. Hull (Trans.), The archetypes and the collective unconscious (Vol. 9ii, pp. 151-181). London, UK: Routledge. (Original work published 1939)

Jung, C. G. (2010). Synchronicity: An acausal connecting principle. In R. F. C. Hull (Trans.), Structure and dynamics of the psyche (Vol. 8, pp. 1-124). Princeton, NJ: Princeton University Press. (Original work published 1960)

Shea, M. J. (2007). Biodynamic craniosacral therapy (Vol. 1). Berkeley, CA: North Atlantic Books.

Sills, F. (2001). Craniosacral biodynamics (Vol. 1). Berkeley, CA: North Atlantic Books.

Sutherland, W. G., \& Wales, A. L. (1990). Teachings in the science of osteopathy. Fort Worth, TX: Sutherland Cranial Teaching Foundation. 